\title{
Hypernatraemia in the first few days: is the incidence rising?
}

\section{A Laing, C M Wong}

\section{Hypernatraemic dehydration in breast fed infants needs to be resolved so that mothers are not discouraged from breast feeding}

$\mathrm{H}$ ypernatraemic dehydration is a potentially lethal condition and is associated with cerebral oedema, intracranial haemorrhage, hydrocephalus, and gangrene. ${ }^{1}$ The infant's plasma sodium concentration is raised predominantly because of loss of extracellular water. In the past, hypernatraemia occurred most often when artificial feeds of too high a sodium concentration were fed to babies. ${ }^{2}$ This was more common in infants who were fed powdered milk, especially if the mother added extra scoops of powder and failed to provide enough water in the mixture. The resultant hypernatraemia may have stimulated the child's thirst, and further feeds high in sodium would exacerbate the problem. Manufacturing reductions in the solute load of infant formulae, brought about by reports from the Department of Health and Social Security on Present day practice in infant feeding (1974) $)^{3}$ and Artificial feeds for the young infant (1980), ${ }^{4}$ did much to reduce the incidence of this problem. Education of the community and production of proprietary milks in liquid form may also have helped to solve this problem.

\section{EPIDEMIOLOGY}

Hypernatraemia was previously thought to be unusual in breast fed babies. Nevertheless, from 1979 to 1989 there were sporadic reports of hypernatraemic dehydration occurring in breast fed babies. $^{5-10}$ In the 1990s there was an increase in the number of breast fed infants reported to have hypernatraemic dehydration. ${ }^{11-17}$ Cooper et $a l^{14}$ described five such infants born between 1991 and 1994 in Ohio, van der Heide et al ${ }^{15}$ two further cases from the Netherlands, $\mathrm{Ng}$ et $a l^{11}$ described five cases in Hong Kong, Livingstone et $a l^{13}$ reported 21 cases in British Columbia between 1991 and 1995, and Paul et al ${ }^{16}$ identified a further two infants in Vellore, India. In the United Kingdom, Oddie et al ${ }^{12}$ added a further eight cases from the Northern Region of England in 1998, and Harding et $a l^{17}$ estimate that in Bristol they see one infant per month with hypernatraemic dehydration.
Over a period of 18 months in Edinburgh, 13 of almost 9000 infants born were admitted to the neonatal unit at less than 3 weeks of age with hypernatraemic dehydration. All were breast fed In our study, the plasma sodium concentrations of these infants ranged from 150 to $173 \mathrm{mmol} / \mathrm{l}$. Seven infants were readmitted having already been discharged home, but six were diagnosed on the postnatal wards before discharge (unpublished data). Few cases have previously been described to occur in hospital. $^{1118}$

It is thought that in the United States too there is an increased infant morbidity caused by inadequate breast feeding, ${ }^{19}$ and this epidemic coincides with a time when breast feeding rates have reached their highest levels of the last half century. Reports of hypernatraemic dehydration have not been confined to the medical literature. The United States recognised the problem in the early 1990s, and identified in an article in the Wall Street Journal that many cases occurred in infants of affluent professional parents. ${ }^{20}$ Time magazine and various American television programmes briefly highlighted this apparently new epidemic.

The incidence of this condition is difficult to ascertain. Even a recent prospective study from Italy fails to answer the question. Manganaro et $a l^{21}$ included all healthy breast fed neonates referred to their neonatal unit, but did not quote the criteria for referral nor the background population from which the referrals came. The infants were weighed on a daily basis from birth until discharge, and staff intervened if the weight loss was greater than $10 \%$. They found that, of 686 neonates referred over a six month period, 53 had a weight loss of $>10 \%$ and 19 had a plasma sodium concentration > $149 \mathrm{mmol} / \mathrm{l}$ (range 150-160 $\mathrm{mmol} / \mathrm{l})$. Maximal weight loss was observed on the third to fourth day in vaginally delivered infants, and the fourth to fifth day in caesarian delivered infants. The study does not record the infants' ages at the time of maximal plasma sodium concentrations.
Hypernatraemia may be associated with decreased fluid intake, ${ }^{22}$ excessive fluid loss, ${ }^{23}$ or excessive sodium intake. ${ }^{24}{ }^{25}$ The last of these was most dramatically established during a mass accidental salt poisoning of infants in March 1962 when there was an error in making up proprietary milk. ${ }^{25}$ Six of the 14 infants who received an excessive sodium load died, and 11 had neurological symptoms. Of the six who died, five had autopsies which showed that the pathology involved widespread damage to the cerebral vasculature. It is therefore not surprising that there have been attempts to establish that the cause of hypernatraemic dehydration in breast fed babies is an unusually high sodium content of maternal breast milk. The sodium content of breast milk at birth is high and declines rapidly over the subsequent days. In 1949 Macy $^{26}$ established that the mean (SD) sodium content of colostrum in the first five days is 22 (12) mmol/l, and of transitional milk from day five to ten is 13 (3) mmol/l, and of mature milk after 15 days is 7 (2) mmol/l. Morton ${ }^{27}$ studied the breast milk of 130 women as they began to breast feed. Women who failed to establish good breast feeding did not experience the normal physiological decrease in breast milk sodium concentration compared with those who had little difficulty in establishing a good milk flow.

Anand et al $^{28}$ studied the breast milk of one mother whose breast fed baby presented at 15 days of age with a serum sodium of $192 \mathrm{mmol} / \mathrm{l}$. On day 18 the mother's breast milk had a sodium content of $31 \mathrm{mmol} / \mathrm{l}$, and on day 23 the sodium concentration was $28 \mathrm{mmol} / \mathrm{l}$. It is tempting to conclude that the high sodium content of the milk was the cause of the problem. Nevertheless the infant was feeding for only five minutes every four hours, and had lost 36\% of birth weight in 15 days. It seems unlikely that such a limited intake of high sodium content milk was sufficient to raise the child's plasma sodium concentration to such a degree. It is more probable that poor suckling by the infant caused the elevated milk sodium concentration. Kini et $a l^{29}$ reported on three infants presenting with hypernatraemic dehydration whose mothers had high breast milk sodium concentrations, but again the volumes of breast milk consumed were very small. All three children were discharged on proprietary milk, and the authors, incorrectly in our view, attributed the infants' problems to the high sodium content of the breast milk. In one of the two cases described by Rowland et al, ${ }^{6}$ the breast milk sodium concentration was also high, but again the infant showed considerable weight loss. While the infant was being breast 
fed by a surrogate mother, the sodium concentration of the breast milk of the biological mother declined dramatically as the volume produced increased. Thullen ${ }^{7}$ also studied a mother whose breast milk volume was exceedingly low with a sodium concentration of 74 mmol/l. During her child's rehydration period, she used a breast milk pump to establish good milk volumes, and the sodium concentration fell to normal levels over two weeks.

Today the evidence suggests that the most common cause of hypernatraemic dehydration is low volume intake of breast milk. The infant becomes dehydrated while the kidneys are mature enough to retain sodium ions. Water loss occurs predominantly through the skin and from the lungs.

\section{"Mothers may be of high intelligence and yet not identify the fact that their infant is poorly hydrated."}

Primary insufficient lactation is rare. Poor milk production is usually due to secondary insufficient lactation, caused by poor milk removal from the breast, which then becomes engorged. ${ }^{30}$ The child may then tire and fail to stimulate further lactogenesis. Small for gestational age or preterm infants suckle less powerfully than appropriately grown term infants. ${ }^{31}$ It has been suggested that the principal cause may be inadequate professional support of lactation, particularly in firstborn children who are breast fed. ${ }^{14}$ van der Heide et $a l^{15}$ attribute the severe weight loss of their two infants to "poor professional support of lactation and lack of weight control". A survey of the literature shows that often the common thread is a mother who is primigravid and has a strong desire to breast feed. ${ }^{56932}$ The problem can still occur in mothers who have previously successfully breast fed infants. ${ }^{19}$ Mothers may be of high intelligence and yet not identify the fact that their infant is poorly hydrated. ${ }^{19}$

\section{CLINICAL PRESENTATION}

The clinical presentation of hypernatraemic dehydration is usually about 10 days, with a range quoted in the literature from three to 21 days. The parents may have failed to identify that the infant is ill, and professionals may also be falsely reassured by the infant's apparent wellbeing. ${ }^{32}$ Signs may be nonspecific, including lethargy ${ }^{528}$ and irritability. ${ }^{33}$ Occasionally there is an acute deterioration, which precipitates the infant's emergency admission to hospital. Chilton ${ }^{32}$ reported on a term infant who exhibited fussiness, low stooling and urination, and a 10\% weight loss on day 5 . The mother was given unspecified breast feeding advice, but by day 7 the child's weight loss was $24 \%$, he was anuric, jaundiced, and pyrexial, and his serum sodium was $182 \mathrm{mmol} / \mathrm{l}$ Evans and Davies ${ }^{34}$ described four breast fed infants who gave no signs of inadequate breast milk intake other than poor weight gain and poor growth in length and head circumference.

During acute isonatraemic or hyponatraemic dehydration, clinicians may rely on sunken eyes and depressed anterior fontanelle as signs of total body water loss. In hypernatraemic dehydration, however, there may be changes in brain cell osmolality and cerebral oedema, and the resultant fullness of the anterior fontanelle may disguise the underlying dehydration. Clinical examination of these infants at presentation is very variable. Some present with lethargy and have an unremarkable examination. Others may be alert and hungry and are clinically dehydrated. Still others may be moribund by the time they arrive at the emergency room.

\section{DIAGNOSTIC CRITERIA}

Given that the condition is difficult to identify clinically, how can paediatricians agree diagnostic criteria and how can they identify all infants in the community who develop hypernatraemic dehydration? Surprisingly little information is available on the normal weight loss to be expected for fully breast fed infants. Maisels and Gifford $^{35}$ weighed 100 fully breast fed infants in the first 3 days of life and found weight loss greater than $10 \%$ in seven. For decades it has been a received wisdom that healthy term infants may lose up to $10 \%$ of their birth weight. There is no doubt that infants can lose more than this amount and be entirely healthy, but it is also of concern that there is a report in the literature of a child with symptomatic hypernatraemia who had apparently lost only $8 \%$ of birth weight. ${ }^{13}$ Given that the condition appears to be more common than previously thought, it seems sensible to capture most of these infants by identifying the population whose weight loss is greater than $10 \%$. This number also has the great advantage of being readily calculated even without electronic aids.

When should these infants be weighed? Again it seems wise to recommend a regimen that is achievable. The literature quotes presentation times from 3 to 21 days. In the United Kingdom, resources in the community are not infinite. Daily weighing from birth may be ideal but impracticable, and may cause parental anxiety. One possibility is to weigh all infants who are breast feeding or partially breast feeding on the same day that the Guthrie test is carried out. The baby will be awake, and can be easily undressed at that time. Clearly if the Guthrie screening test is carried out on day 5 or 6, some infants who present with very early onset disease will become hypernatraemic before the Guthrie test has been carried out.

\section{"Daily weighing from birth may be ideal but impracticable, and may cause parental anxiety."}

Critics of weighing babies will rightly point out that scales in hospital and the community vary in their accuracy. Nevertheless this seems to be the least unsatisfactory method of identifying infants at risk of developing severe dehydration. Each neonatal service should ensure that the scales available provide quality assured metric weights.

It is also recognised that there is individual variation in laboratory measurements of plasma sodium. When therefore is a hypernatraemic infant worryingly hypernatraemic? Most of the infants who have come to harm from the disorder have had plasma sodium concentrations significantly higher than 150 $\mathrm{mmol} / \mathrm{l}$. As a first step therefore it may be reasonable to accept this level as the one that triggers admission to hospital. In Edinburgh we have this year embarked on an extensive audit that will identify how many breast feeding infants exhibit weight loss greater than $10 \%$ on the day that their Guthrie test is carried out. These infants will then be entered on a risk chart and will be weighed on a daily basis. Those infants who show a weight loss greater than $12 \%$ will all be examined by a paediatrician, and the plasma sodium concentration will be measured. Only by embarking on such an audit can we begin to answer some of the questions that currently challenge us.

\section{MORBIDITY AND MORTALITY}

There are no studies in the literature describing long term follow up of breast fed infants who have suffered hypernatraemic dehydration. Nevertheless the condition carries an acute morbidity and mortality. Arboit and Gildengers ${ }^{36}$ described an infant whose serum sodium peaked at $180 \mathrm{mmol} / \mathrm{l}$ who developed a temporary right sided facial palsy. Rowland et $a l^{6}$ reported on a child with a serum sodium of $174 \mathrm{mmol} / \mathrm{l}$ who had apnoea and bradycardia, and another child whose sodium concentration was $206 \mathrm{mmol} / \mathrm{l}$ who displayed seizures, hypertension, and disseminated intravascular coagulation. Clarke and Sibert ${ }^{37}$ described a 12 day old child who presented with a serum sodium of 176 $\mathrm{mmol} / \mathrm{l}$ who evinced no neurological problems, but after establishing full oral 
feeds was diagnosed as having necrotising enterocolitis. More dramatic still, Cooper et $a l^{14}$ reported on five infants with hypernatraemic dehydration, of whom two were apparently normal, one had amputation of the left leg secondary to an iliac artery thrombus, one had decreased facial movement, and one had "EEG slowing", multiple cerebral infarctions, and seizures. The brain damage may be caused by cerebral oedema, intracranial haemorrhages, haemorrhagic infarcts, and thromboses. These can be identified in babies by using magnetic resonance imaging. ${ }^{38}$

The paper of Kaplan et al ${ }^{1}$ outlines the course of two infants who died. The first presented at 9 days of age with a plasma sodium of $191 \mathrm{mmol} / \mathrm{l}$, suffered seizures, massive intraventricular haemorrhage, and multiple dural thromboses and died on day 12. The second presented on day 13 with a plasma sodium concentration of $180 \mathrm{mmol} / \mathrm{l}$ and showed on computed tomography scanning multiple areas of intraventricular, periventricular, and cortical haemorrhage. This second child died on day 16.

\section{TREATMENT}

Some complications, especially seizures, occur most commonly during treatment. $^{9183940}$ It is recognised that the mainstay of treatment is to rehydrate the child very slowly. If the staff caring for the child attempt to correct the high sodium concentration quickly, there is severe risk of osmotic changes in the brain, which can exacerbate the cerebral oedema, thus adding to potential brain damage.

At presentation, a full clinical assessment of the infant is made. If the infant appears well, then slow rehydration at a rate of $100 \mathrm{ml} / \mathrm{kg} /$ day can be carried out using expressed breast milk or proprietary milk or a combination of both. Although many mothers of infants with hypernatraemic dehydration choose to bottle feed their infants thereafter, it is possible to establish or re-establish successful breast feeding once the child has been rehydrated. $^{7}$

If the child is unwell, rehydration should be carried out intravenously. Little has been published on recommended regimens for intravenous rehydration of such a child. In 1975, Banister et $a l^{23}$ reported on the intravenous treatment of 38 infants with severe hyperosmolar dehydration and hypernatraemia. Infants rehydrated at a rate of 150 $\mathrm{ml} / \mathrm{kg} /$ day were more likely to develop convulsions and peripheral oedema than the infants whose fluid intake was restricted to $100 \mathrm{ml} / \mathrm{kg} /$ day.

A collapsed child may require to be resuscitated initially with $20 \mathrm{ml} / \mathrm{kg}$ colloid or $0.9 \%$ saline infused over half an hour. If the child is not in shock, then rehydration may be started intravenously using $0.9 \%$ saline at $100 \mathrm{ml} / \mathrm{kg} /$ day provided that the plasma glucose concentration remains greater than 2.5 $\mathrm{mmol} / \mathrm{l}$. Plasma urea and electrolyte concentrations are measured 6 hourly. In our experience it is not uncommon to see the plasma urea concentrations fall quickly in the first 24 hours but little change is seen in the plasma sodium concentration. After 24 hours, our regimen recommends continuing rehydration at the same rate, but using $0.45 \%$ saline in 5-10\% dextrose. Thereafter oral rehydration with breast milk or artificial milk should be possible, with cautious increases in volume rates as the plasma sodium concentration decreases to normal levels in the subsequent days.

\section{DISCUSSION AND RECOMMENDATIONS}

Are these numbers genuinely increasing or are we finally beginning to identify a hitherto unrecognised condition? It seems unlikely that there are small pockets of this condition in the developed and developing world. Far more probable is the hypothesis that what is recorded regularly in Vancouver, New York, Bristol, and Edinburgh is also seen regularly elsewhere, but is under-reported.

It is possible that hypernatraemic dehydration has always been a problem in breast fed infants and has had inadequate exposure in the medical literature. It is also possible that this condition has become much more common in the last decade. Why should this be? Does it merely reflect an increased prevalence of breast feeding in our community? This may be a component, but it is important to note that the medical literature on this subject does not come predominantly from Scandinavia or Australia where breast feeding is much more widespread than it is in the United Kingdom.

It was shown in Canada that, when the mean length of stay of newborns in hospital was reduced from 4.2 to 2.7 days, the readmission rates rose from 27 to 38 per 1000 , and that the risk of readmission for dehydration, jaundice and feeding problems, and poor weight gain was particularly high. ${ }^{41}$ Although the increasing prevalence of breast feeding in some areas is a probable contributory factor, shorter postpartum stays in hospital and under-resourced community supports may be the combination that is currently failing our newborn infants. Cooper et $a l^{14}$ described a cluster of five infants with hypernatraemic dehydration over a five month period and opined that this represented an increase in observed cases from 1990 to 1994. During this time the postnatal inpatient stay of mother and child decreased from 2.4 to 1.7 days.

Hypernatraemic dehydration is most commonly seen in term infants. On the other hand, preterm and small for gestational age infants who have poor suckling capabilities are at particular risk. They require to be identified on the regular postnatal wards to ensure that community follow up is even more vigilant. The mother is shown how to hand express breast milk into a sterilised bowl, jug, or bottle. In the United Kingdom, breast pumps may be provided for mothers in cases where breast feeding success is borderline and hand expression of milk is only partially successful.

First time mothers often require much patient reassurance and practical advice in the technique of breast feeding. In the 1980s it was not uncommon for first time mothers who had delivered vaginally to remain in hospital for several days before returning home. During this time, those who wished to breast feed could receive the intensive support they required to ensure that the child was positioned correctly, attached appropriately to the breast, and that suckling was successful. Verbal discussions at these times could give the mother the knowledge that she required to address the infant's needs. Now it is the norm for a breast feeding mother to take her baby home after a six hour discharge or a DOMINO delivery (domiciliary midwife in and out), or at any rate before two days have elapsed. It then falls to the community midwives to identify in a short visit that there is a feeding problem, and to try to advise the mother how to increase the quantity of breast milk consumed by the infant. Are the resources in our community sufficient to allow midwifery staff to fulfil their function adequately?

Close observation is central to the evaluation of the adequacy of breast feeding. Such observation requires time. The midwife notes the wide mouthed approach of the hungry baby, the tongue underneath the nipple, the chin pressed in to the breast tissue, and the nose high. Often a breast feed begins with rapid sucks, about two per second, but this short period is followed by stronger more sustained sucking with pause periods for breath, during which the infant remains latched on to the breast. A successful feed may last 10-40 minutes, with perhaps a rest of 5-10 minutes in the middle. As a practical guideline, feeds lasting less than 10 minutes may be regarded as "snack feeds", although the duration of a breast feed gives no indication of the volume of milk delivered. In the first 48 hours of a baby's life, when demand may exceed supply, the infant may be irritable at the end of a feed. Older babies tend to appear contented at the end of a satisfactory feed and will often go to sleep. This, however, must not be confused with the lethargy of an infant with hypernatraemic dehydration; such a child will show much less powerful rhythmic sucking, will feed for short periods of time, and then appears to be satiated even after small volumes of intake. 
In the past, weighing infants in the community has received bad press from some who feel that the mother is put under more pressure to perform successfully, which in turn can raise her anxieties and impede her success in breast feeding. Nevertheless, with discharge home occurring earlier, an adequate supply of weighing scales should be made available to community midwives so that they can monitor carefully the progress of any infants in the community who are small, preterm, or who have been identified as having some feeding difficulties. Risk charts may be drawn up as an educational tool. They can highlight maternal associations such as primigravidity, breast feeding, breast engorgement, flat, inverted, or painful nipples, and failure of transitional milk to appear by four days. Associated features of the neonate include the infant going to the breast infrequently or for short times, infrequent passage of urine $(<6$ times a day) and stool $(<4$ times a day), delayed passage of yellow seedy stools (after four days), jaundice, lethargy, irritability, fever, multiple pregnancy, Down's syndrome, birth asphyxia, and cleft palate.

Accounts in the medical literature are often in the form of case reports and are not explicit about the population size and birth rates involved. Neither are breast feeding rates discussed. There is a strong need to audit this condition, and first we must agree on a strict definition of the condition. Such an audit should identify infants who have lost more than $10 \%$ of birth weight. These infants should have a plasma sodium concentration measured and a robust support system put in place to ensure that they enjoy successful breast feeding over the subsequent days. Those who have a plasma sodium concentration greater than $149 \mathrm{mmol} / \mathrm{l}$ should be admitted to a children's hospital for further care. We further recommend that the time of presentation is carefully studied, and that such cases are analysed as early onset (first 7 days of life) and late onset (days 8 to 28 after delivery). This condition may lend itself perfectly to a future study coordinated by the British Paediatric Surveillance Unit.

Meanwhile, an intensive education programme should be put in place throughout the United Kingdom to raise the awareness of parents, doctors, midwives, nurses, and health visitors that hypernatraemic dehydration is a potentially lethal condition which is not rare but is often difficult to diagnose clinically. The most reliable and simple means at the disposal of professional staff is to weigh the child. It is recognised that multiple weighing of infants in the community may cause parental anxiety and could result in a mother abandoning breast feeding altogether. On the other hand, it is a failure of care to allow infants both in hospital and in the community to suffer the morbidity and mortality of hypernatraemic dehydration when this could be identified by calculating the percentage weight loss experienced by the infant.

We advocate that all breast fed infants, irrespective of whether they are regarded as high or low risk for developing hypernatraemic dehydration, should be weighed at least once several days after discharge. Perhaps this could be carried out at the same time as the Guthrie screening test. Doctors, midwives, community nurses, and health visitors should be trained to identify the "at risk" child, whose feeding is not progressing normally. We should be meticulous in taking a careful history of feeding frequency, length of time at the breast, adequacy of maternal milk flow, frequency of urinary passage, and the timing of changing stool from meconium to a transitional milk stool. Any infant who appears to have some difficulties in establishing successful breast feeding should be identified and details entered on a risk chart. The hospital and community should then be committed to providing the resources to support the mother and child, including the provision of expert advice on breast feeding, and weighing the child as often as is considered necessary by the lead professional. If there is a weight loss of more than $10 \%$, the infant should be weighed on a daily basis until a normal growth velocity can be recorded. It is surely safer for the child to be identified by a diligent midwife as having lost more than 10\% weight than to be allowed to develop hypernatraemic dehydration thus risking brain damage, limb amputation, or death.

Breast feeding undoubtedly produces health advantages for infant and mother. We are right to promote expansion of breast feeding in the developed and developing worlds. On the other hand, it is not acceptable to gloss over individual breast feeding tragedies lest the resultant publicity discourages mothers from choosing to breast feed their babies. Rather we must address the underlying problems that may arise during breast feeding, identify resources of finance and expertise to eliminate these, and continue to recommend breast feeding as the best method of nourishing healthy infants. Given the numbers of children involved, this topic must receive a very high priority in our health strategies.

Arch Dis Child Fetal Neonatal Ed 2002;87: F158-F162

\section{Authors' affiliations}

I A Laing, C M Wong, Simpson Memorial Maternity Pavilion, Lauriston Place, Edinburgh EH3 9YW, Scotland, UK
Correspondence to: Dr Laing, Simpson Centre for Reproductive Health, Royal Infirmary at Little France, 51 Little France Crescent, Edinburgh EH16 4SU, Scotland, UK : ian.laing@luht.scot.nhs.uk

\section{REFERENCES}

1 Kaplan JA, Siegler RW, Schmunk GA. Fatal hypernatremic dehydration in exclusively breast-fed newborn infants due to maternal lactation failure. American Journal of Forensic Medicine and Pathology 1998;19:19-22.

2 Chambers TL, Steel AE. Concentrated milk feeds and their relation to hypernatraemic dehydration in infants. Arch Dis Child 1975;50:610-15.

3 Department of Health and Social Security Report on Health and Social Subjects. 9. Present day practice in infant feeding. London: HMSO, 1974: 8-10.

4 Department of Health and Social Security Report on Health and Social Subjects. 18. Artificial feeds for the young infant. London: HMSO, 1980:40-2.

5 Clarke TA, Markarian M, Griswold W, et al. Hypernatremic dehydration resulting from inadequate breast-feeding. Pediatric 1979:63:931-2

6 Rowland TW, Zori RT, Lafleur WR, et al. Malnutrition and hypernatremic dehydration in breast-fed infants. JAMA 1982;247:1016-17

7 Thullen JD. Management of hypernatremic dehydration due to insufficient lactation. Clin Pediatr 1988;27:370-2.

8 Jaffe KM, Kraemer M, Robison MC. Hypernatremia in breast-fed newborns. West J Med 1981;135:54-5.

9 Roddey OF Jr, Martin ES, Swetenburg RL. Critical weight loss and malnutrition in breast-fed infants. American Journal of Diseases of Children 1981;135:597-9.

10 Marino R, Gourji S, Rosenfeld W. Neonatal metabolic casebook. Hypernatremia and breast feeding. J Perinatol 1989;9:451-3.

$11 \mathrm{Ng} \mathrm{PC}$, Chan HB, Fok TF, et al. Early onset of hypernatraemic dehydration and fever in exclusively breast-fed infants. J Paediatr Child Health 1999:35:585-7.

12 Oddie S, Richmond S, Coulthard M Hypernatraemic dehydration and breast feeding: a population study. Arch Dis Child 2001;85:318-20.

13 Livingstone VH, Willis CE, Abdel-Wareth LO, et al. Neonatal hypernatremic dehydration associated with breast-feeding malnutrition: a retrospective survey. Can Med Assoc J 2000; 162:647-52

14 Cooper WO, Atherton HD, Kahana M, et al. Increased incidence of severe breastfeeding malnutrition and hypernatremia in a metropolitan area. Pediatrics 1995; 96:957-60.

15 van der Heide PA, Toet $M C$ Diemen-Steenvoorde JA, et al. Hypertonic dehydration in "silent" malnutrition of breast-fed infants. Ned Tijdschr Geneeskd 1998;142:993-5.

16 Paul AC, Ranjini K, Muthulakshmi, et al Malnutrition and hypernatraemia in breastfed babies. Ann Trop Paediatr 2000;20:179-83

17 Harding D, Cairns P, Gupta S, et al. Hypernatraemia: why bother weighing breast fed babies? Arch Dis Child Fetal Neonatal Ed 2001;85:F145

18 Chaudhary R, Twaddle S, Levi R, et al. Hypernatremic dehydration in breast-fed infants. Paediatrics Today 1998:6:85-7.

19 Neifert MR. Prevention of breastfeeding tragedies. Pediatr Clin North Am 2001;48:273-97.

20 Helliker K. Dying for milk: some mothers trying in vain to breast feed, starve their infants. The Wall Street Journal 22 Jul 1994;A1.

21 Manganaro R, Mami C, Marrone T, et al. Incidence of dehydration and hypernatremia in exclusively breast-fed infants. J Pediatr $2001 ; 139: 673-5$ 
22 Pickel S, Anderson C, Holliday MA. Thirsting and hypernatremic dehydration: a form of child abuse. Pediatrics 1970;45:54-9.

23 Banister A, Matin-Siddiqi SA, Hatcher GW Treatment of hypernatraemic dehydration in infancy. Arch Dis Child 1975:50:179-86.

24 Colle E, Ayoube E, Raile R. Hypertonic dehydration (hypernatraemia): the role of feeding high in solutes. Pediatrics 1958;22:5

25 Finberg I, Kiley J, Luttrell CN. Mass accidental poisoning in infancy. JAMA 1963; 184:187-90.

26 Macy IG. Composition of human colostrum and milk. American Journal of Diseases of Children 1949:78:589-603.

27 Morton JA. The clinical usefulness of breast milk sodium in the assessment of lactogenesis. Pediatrics 1994;93:802-6.

28 Anand SK, Sandborg C, Robinson RG, et al. Neonatal hypernatremia associated with elevated sodium concentration of breast milk. J Pediatr 1980;96:66-8.
29 Kini N, Zahn S, Werlin SL. Hypernatremic dehydration in breast-fed infants. Wis Med J 1995;94: 143-5.

30 Waller $\mathbf{H}$. The early failure of breastfeeding: a clinical study of its causes and their prevention. Arch Dis Child 1946;21:1-12

31 Edmonson MB, Stoddard JJ, Owens LM. Hospital readmission with feeding-related problems after early postpartum discharge of normal newborns. JAMA 1997;278:299303.

32 Chilton LA. Prevention and management of hypernatremic dehydration in breast-fed infants. West J Med 1995;163:74-6.

33 Peters JM. Hypernatremia in breast-fed infants due to elevated breast milk sodium. J Am Osteopath Assoc 1989;89: $1165-70$.

34 Evans TJ, Davies DP. Failure to thrive at the breast: an old problem revisited. Arch Dis Child 1977;52:974-5
35 Maisels MJ, Gifford K. Breast feeding, weight loss, and jaundice. J Pediatr 1983; 102:117-18

36 Arboit JM, Gildengers E. Breast-feeding and hypernatremia. J Pediatr 1980;97:335-6.

37 Clarke AJ, Sibert JR. Hypernatraemic dehydration and necrotizing enterocolitis. Postgrad Med J 1985;61:65-6.

38 Korkmaz A, Yigit S, Firat $M$, et al. Cranial MRI in neonatal hypernatraemic dehydration. Pediatr Radiol 2000;30:323-5.

39 Ernst JA, Wynn RJ, Schreiner RL. Starvation with hypernatremic dehydration in two breast-fed infants. J Am Diet Assoc 1981;79:126-30.

40 Ghishan FK, Roloff JS. Malnutrition and hypernatremic dehydration in two breast-fed infants. Clin Pediatr 1983;22:592-4

41 Liu S, Wen SW, McMillan D, et al. Increased neonatal readmission rate associated with decreased length of hospital stay at birth in Canada. Can J Public Health 2000;91:46-50.

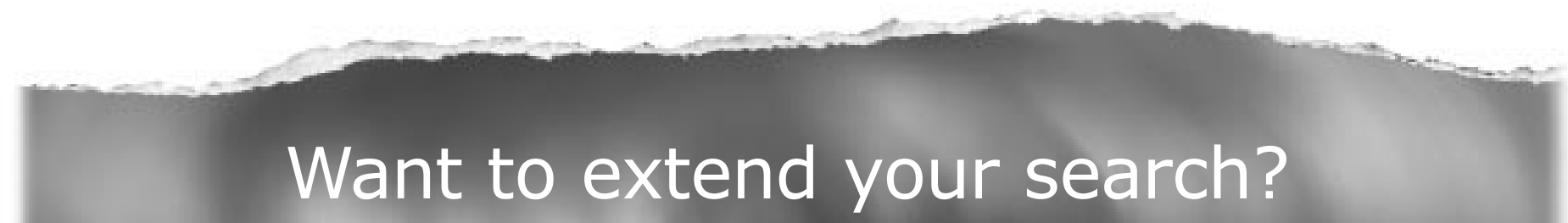

Cross journal searching

If you can't find what you are looking for in Archives of Disease in Childhood you can extend your search across many of the more than 200 journals available for selection. You can restrict your search to specific subject areas (eg, clinical medicine, basic research), or select specific journals, or search all available titles.

www.archdischild.com 